Keywords: stainless steel, surface treatment, passivation, tritium, mass spectroscopy

Retention: Permanent

\title{
Evaluation of Alternate Stainless Steel Surface Treatments for Mass Spectroscopy and Other Tritium Systems
}

E.A. Clark

C.B. Mauldin

K.C Neikirk

29 February 2012

Savannah River National Laboratory Savannah River Nuclear Solutions, LLC Aiken, SC 29808

Prepared for the U.S. Department of Energy under contract number DE-AC09-08SR22470.

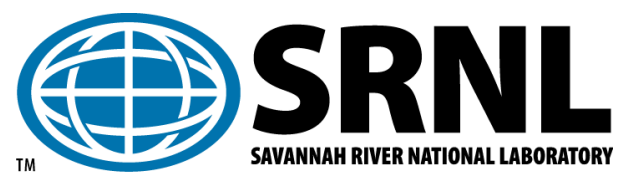




\section{DISCLAIMER}

This work was prepared under an agreement with and funded by the U.S. Government. Neither the U.S. Government or its employees, nor any of its contractors, subcontractors or their employees, makes any express or implied:

1. warranty or assumes any legal liability for the accuracy, completeness, or for the use or results of such use of any information, product, or process disclosed; or

2. representation that such use or results of such use would not infringe privately owned rights; or

3. endorsement or recommendation of any specifically identified commercial product, process, or service.

Any views and opinions of authors expressed in this work do not necessarily state or reflect those of the United States Government, or its contractors, or subcontractors.

\section{Printed in the United States of America \\ Prepared for \\ U.S. Department of Energy}




\section{EXECUTIVE SUMMARY}

There are specific components in the SRS Tritium Facilities that are required to introduce as few chemical impurities (such as protium and methane) as possible into the process gas. Two such components are the inlet systems for the mass spectroscopy facilities and hydrogen isotope mix standard containers. Two vendors now passivate stainless steel components for these systems, and both are relatively small businesses whose future viability can be questioned, which creates the need for new sources. Stainless steel containers were designed to evaluate alternate surface treatment vendors for tritium storage and handling for these high purity tritium systems. Five vendors applied their own "best" surface treatments to two containers each- one was a current vendor, another was a chemical vapor deposited silicon coating, and the other three were electropolishing and chemical cleaning vendors. Pure tritium gas was introduced into all ten containers and the composition was monitored over time. The only observed impurities in the gas were some HT, less $\mathrm{CT}_{4}$, and very small amounts of $\mathrm{T}_{2} \mathrm{O}$ in all cases. The currently used vendor treated containers contained the least impurities. The chemical vapor deposited silicon treatment resulted in the highest impurity levels.

Sampling one set of containers after about one month of tritium exposure revealed the impurity level to be nearly the same as that after more than a year of exposure- this result suggests that cleaning new stainless steel components by tritium gas contact for about a month may be a worthy operation. 


\section{CONTENTS}

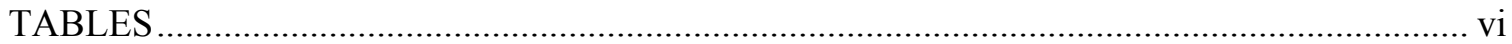

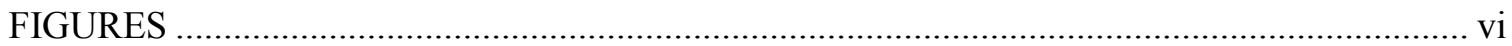

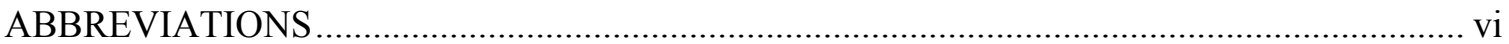

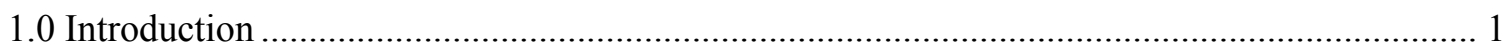

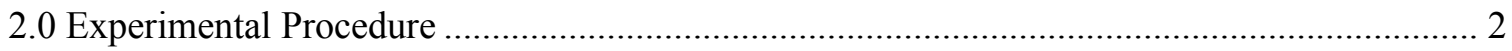

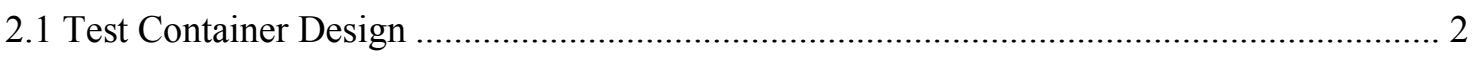

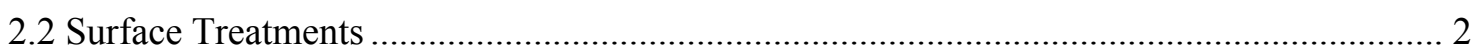

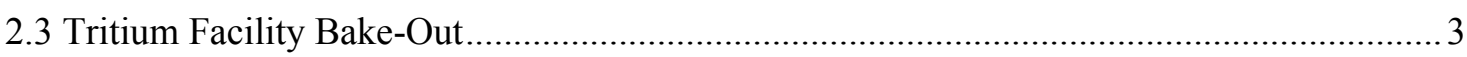

2.4 Tritium Gas Introduction and Composition Monitoring ..................................................... 3

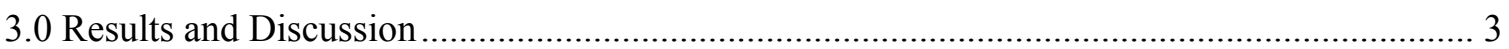

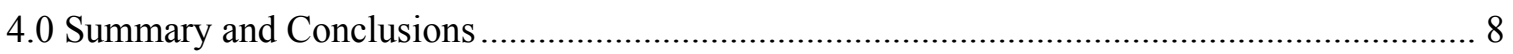

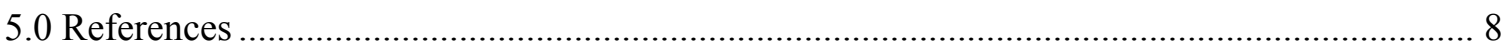




\title{
TABLES
}

Table 2-1.Vendor Designation and general description of surface treatment processes

\section{FIGURES}

Figure 2-1. Photograph and engineering drawing of test container/valve assembly.................... 2

Figure 3-1. Species concentration versus exposure time for TK containers. ................................. 4

Figure 3-2. Species concentration versus exposure time for RK containers ................................. 4

Figure 3-3. Species concentration versus exposure time for CL containers.................................. 5

Figure 3-4. Species concentration versus exposure time for AT containers ................................ 5

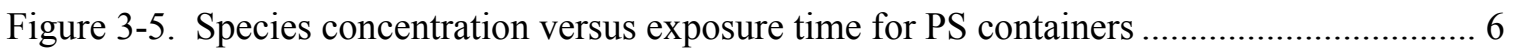

Figure 3-6. Total impurity concentration versus exposure time for all containers....................... 7

\author{
ABBREVIATIONS \\ SRNL Savannah River National Laboratory \\ SRS US Department of Energy Savannah River Site
}




\subsection{Introduction}

The surfaces of specific systems and components that handle high purity tritium gas in the SRS Tritium Facilities are treated before use by a process termed "passivation". Currently, passivation is performed by one of two approved vendors using proprietary processes. Both vendors are small businesses, and if one or both vendors cease operation, the Tritium Facility would be in a difficult position to procure specialized components. The goal of the study reported here is to evaluate other commercially available stainless steel surface treatments and to determine whether one or more may be an acceptable replacement for the currently used vendors.

The nomenclature in the field of passivation of stainless steels, and other usage of the word, is confusing. The original development of stainless steels resulted from the realization that sufficient chromium content ( $>12 \%$ by mass) in iron causes a transparent chromium oxide surface film to form natively (on its own) in air. This surface film imparts significant corrosion resistance to the alloy. The first stainless steels were developed in the early 1900's, and by now stainless steels form a broad class of iron-based alloys. Some of the most important stainless steels contain about $18 \%$ chromium and $8 \%$ nickel, and are termed the "austenitic" stainless steels, or "18-8" stainless steels. These are the materials that are used for most of the SRS tritium facility. Not only are they corrosion resistant, they are also resistant to so-called "hydrogen embrittlement"- they resist cracking caused by contact with gaseous hydrogen isotopes when tensile applied or residual stresses are present. Common vacuum and gas-handling components are made from austenitic steels, and the vast majority of the SRS Tritium Facility that forms the main barrier that confines tritium gas is fabricated from this material.

The $\mathrm{Cr}_{2} \mathrm{O}_{3}$ rich film that covers stainless steel is termed the "passive film". As discussed above, the sufficiently high chromium content allows this film to form on stainless steel surfaces exposed to air without any other processing. During the development of industrial production of stainless steels it was found advantageous to clean stainless steel during and after processing in the foundry- partly to remove various oxides formed when hot metal is exposed to the air in a steel plant, and partly to remove metallic and non-metallic impurities from the surface caused by contact with items such as rolling mills used for stainless steels and other materials, especially iron alloys. Surface cleaning processes include salt-bath $(\mathrm{NaOH})$ descaling, and "pickling" by sulfuric acid [1]. There are several so-called "passivation treatments" [1,2] involving immersion in hot baths of nitric or citric acid, that help to form a more stable surface passive film [3]. Also, sometimes surfaces are cleaned by adding a small amount of fluoride ion to nitric acid [2]. Electropolishing is also used as a means of cleaning and passivating stainless steels [4]. Thus, the term "passivation" can refer either to the type of passive film that forms naturally on stainless steel or to one or more of the processes to clean or ensure the passive film on stainless steel surfaces. Whatever passivation process is used, the intent is to impart the most corrosion resistance to the passive film on the stainless steel surface and to ensure the film's integrity.

There have been several studies of cleaning stainless steel with the intent of reducing chemical impurity introduction into systems made with stainless steel, including fusion tokomaks [5], and particle accelerators [6]. There have been specific studies of stainless steel surface treatments for reducing hydrogen outgassing $[7,8]$. One study developed a thermal passivation method, in which Type 316 stainless steel was held in the range 525 to $775 \mathrm{Kelvin}\left(252^{\circ} \mathrm{C}\right.$. to $502{ }^{\circ} \mathrm{C}$. and oxygen partial pressure is between $5^{*} 10^{-7}$ to $10^{-5} \mathrm{~Pa}\left(4^{*} 10^{-9}\right.$ torr to $8^{*} 10^{-8}$ torr) [9]. This method improved the resistance to crevice corrosion and was also suggested for stainless steel for high vacuum applications. Several studies illustrate the importance of surface cleaning and treatment on reducing the appearance of protium and methane in tritium gas containers $[10,11,12]$. One of 
these studies employed an aluminum ion implanted $\mathrm{Al}_{2} \mathrm{O}_{3}$ film [12]. Another study of stainless steel containers of mixes of $\mathrm{H}_{2}$ and $\mathrm{D}_{2}$ showed that nitric acid passivation or citric acid passivation alone are insufficient passivate the surface enough to prevent isotope exchange of $\mathrm{H}$ and $\mathrm{D}$, and that electropolishing does passivate the surface for this isotope exchange [13]. It is clear that different surface treatments can alter the stainless steel surface structure and its properties, and specific surface structures reduce the amount of protium and methane in-growth in a container of tritium [10].

The purpose of this study was to use an applied engineering approach to evaluate whether alternate vendors of various stainless steel surface treatments could treat otherwise identical test tritium gas containers such that the growth of impurities in the gas are about the same or less than one of the currently used passivation vendors.

\subsection{Experimental Procedure}

\subsection{Test Container Design}

Test container/valve assemblies were designed per ASME B31.3 for this study (Fig. 2-1). Besides being simple and inexpensive, this container design assured that the interior would be easily surface treated by whatever method was used. The basis was a standard $23 / 4$ " Conflat ${ }^{\circledR}$ flange half nipple, with a full penetration weld used to attach the end cap. Type 304L stainless steel was used, and the internal volume of each container was about $62 \mathrm{~cm}^{3}$. The valve was a Nupro B series bellows valve, part \#SS-4BG-18701-TECH. The design pressure was 100 psig at $100{ }^{\circ} \mathrm{F}$. The valve was fillet welded to one side of the Conflat ${ }^{\circledR}$ flange, after machining the flange to accept the valve. In all, fifteen container/valve assemblies were procured.

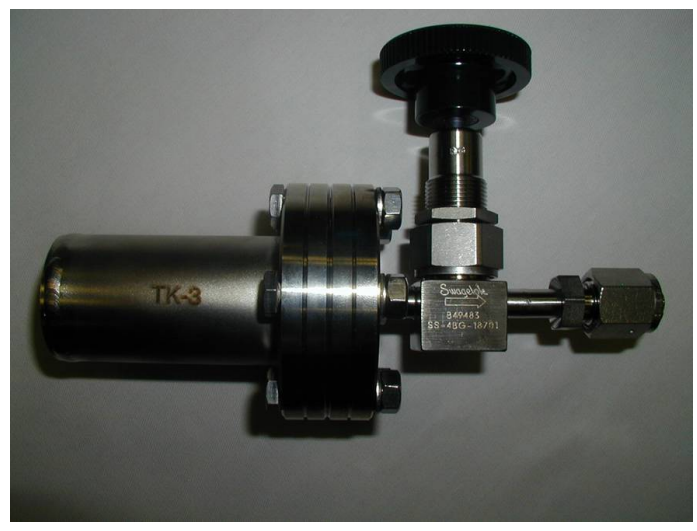

a.

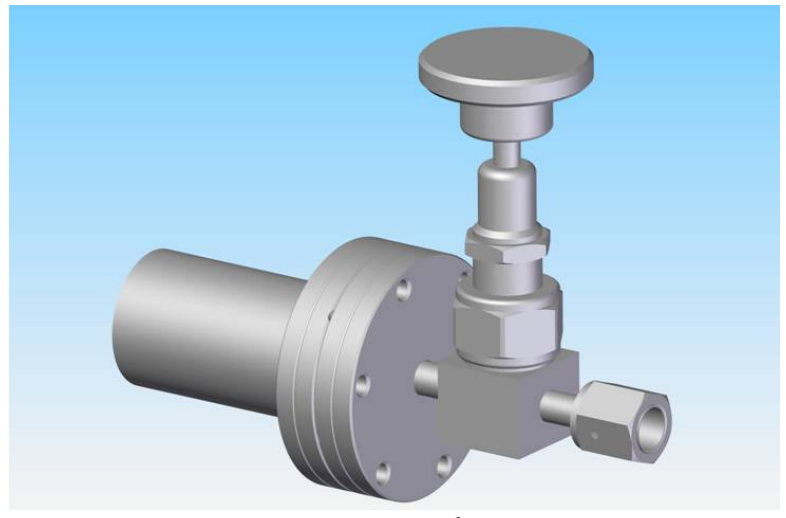

b.

Figure 2-1. Photograph (a) and engineering drawing (b) of test container/valve assembly.

\section{2 $\underline{\text { Surface Treatments }}$}

Five vendors were selected to treat the interior surfaces of the containers; each vendor treated three containers. (This report presents results of two containers from each vendor; one from each surface treatment was not used because of scheduling constraints in the Tritium Facility.) The flanges and valves were disassembled at SRNL, and both remaining parts of each container were sent to the vendor and treated- including the valve body. Each vendor was contracted to perform 
its best effort to clean the parts for high purity gas service, using their "standard" process for this task (Table 2-1). Vendor RK was chosen to test a fundamentally different type of surface treatment- a chemical-vapor deposited (CVD) silicon coating. Vendor TK was one of the currently used passivation vendors, and this treatment serves as the control for this study. The other three vendors used various types of pre-cleaning followed by electropolishing followed by acid washing and water rinsing. (The surface treatment methods are not described in detail because all of the vendors used proprietary processes.)

Table 2-1. Vendor Designation and general description of surface treatment process

\begin{tabular}{|c|l|}
\hline Vendor Designation & General process description \\
\hline TK & One of current vendors for Tritium facility \\
\hline RK & Chemical vapor deposition of silicon \\
\hline CL & Electropolish/acid clean/water rinse \\
\hline AT & Electropolish/acid clean/water rinse \\
\hline PS & Electropolish/acid clean/water rinse \\
\hline
\end{tabular}

After the parts were returned and reassembled, the assembly body and valve seat leak rates were tested. All were acceptable for service. The valve seat leak rates for RK were somewhat higher than the other vendors; however they too were acceptable for these experiments (and to the Tritium Facility).

\subsection{Tritium Facility Bake-Out}

After transferring the containers to the Tritium Facility, they underwent a vacuum bake out normally performed on such containers for tritium use. They were evacuated, and heated using heat tape to about $120{ }^{\circ} \mathrm{C}$ for 24 hours. This bake-out removes much of the adsorbed water on the interior surfaces. This procedure would normally been done on similar parts for tritium service, so it was performed on these test containers.

\subsection{Tritium Gas Introduction and Composition Monitoring}

All containers were filled with $99.92 \%$ tritium to 700 torr by the Tritium Facilities Analytical Laboratory. The main impurity at fill was HT. One set of five was filled in March 2008, and the other set was filled in April 2009. Samples of gas from each container were sampled and assayed by the facility mass spectrometer.

\subsection{Results and Discussion}

The only species detected in any of the samples other than $\mathrm{T}_{2}$ was $\mathrm{HT}_{1} \mathrm{CT}_{4}$, and $\mathrm{T}_{2} \mathrm{O}$ (Figures 3-1, $3-2,3-3,3-4,3-5)$. ( ${ }^{3} \mathrm{He}$ from tritium decay is not reported here.) The species concentration with exposure time was very similar comparing the two containers of each surface treatment vendor. The majority species was HT in all cases, followed by $\mathrm{CT}_{4}$, and much smaller concentration of $\mathrm{T}_{2} \mathrm{O}$. These results are remarkably similar to an earlier study [10], in which the main impurities found in stainless steel containers were $\mathrm{HT}$ and $\mathrm{CT}_{4}$.

Another observation from the first series of containers ("a" in graphs) is that the impurity concentration after about 42 days is similar to that after a year or longer. This suggests that new 
containers could be cleaned by purposely filling with tritium for a month or two, and then evacuating the gas.

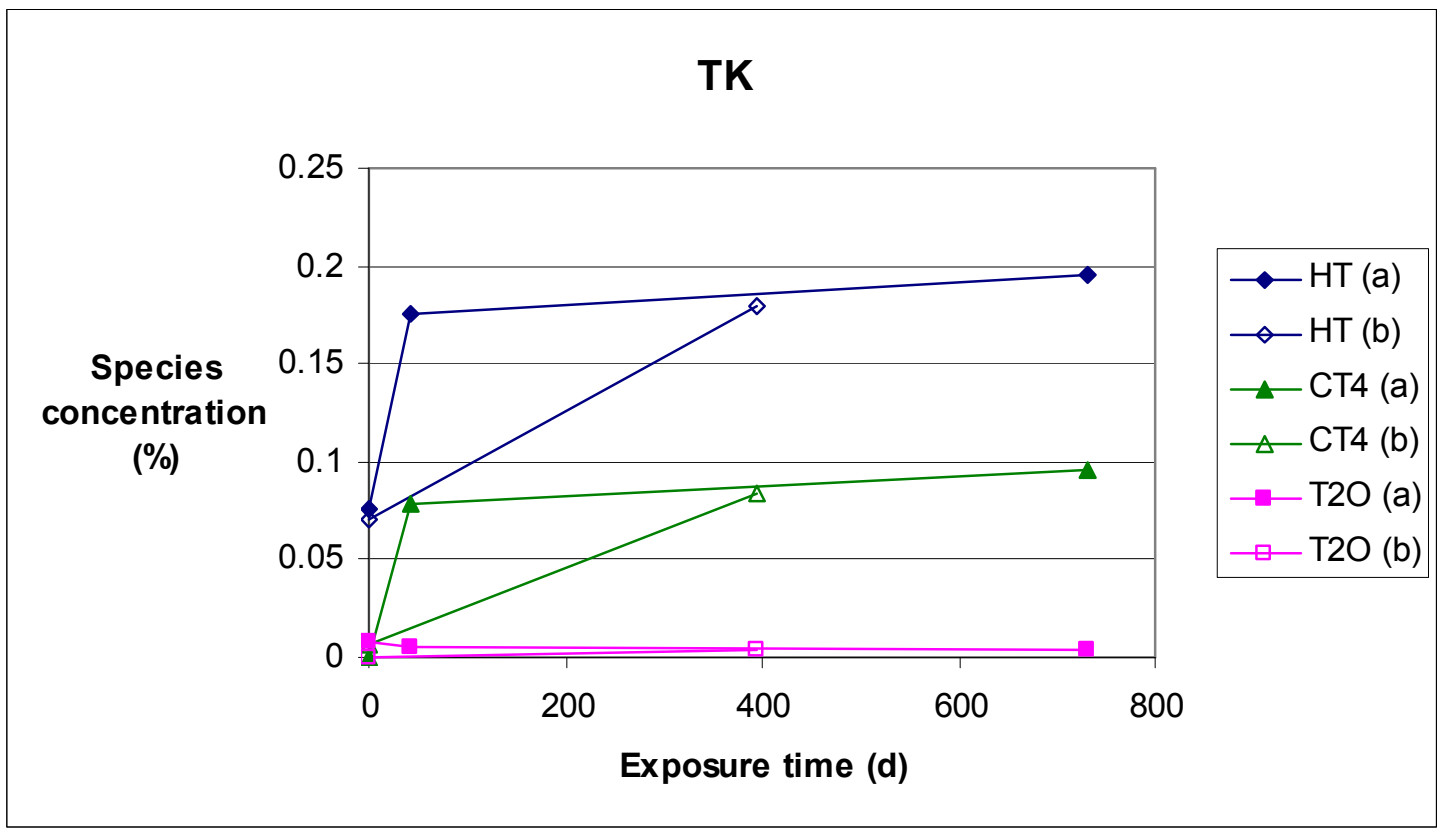

Figure 3-1. Species concentration (mole percent) versus exposure time for two TK containers (a and b); species indicated in legend.

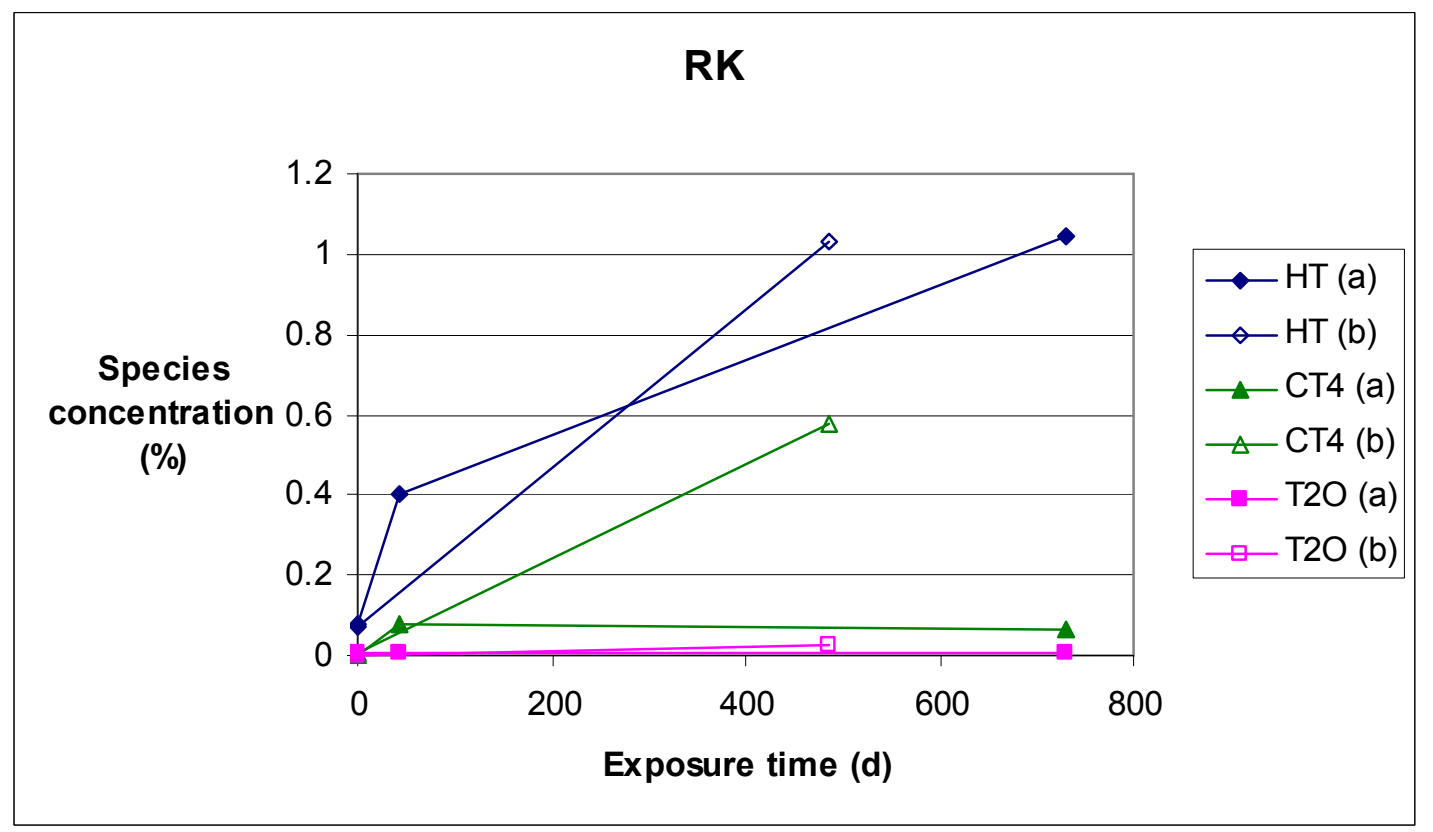

Figure 3-2. Species concentration (mole percent) versus exposure time for two RK containers ( $a$ and $b)$; species indicated in legend. 


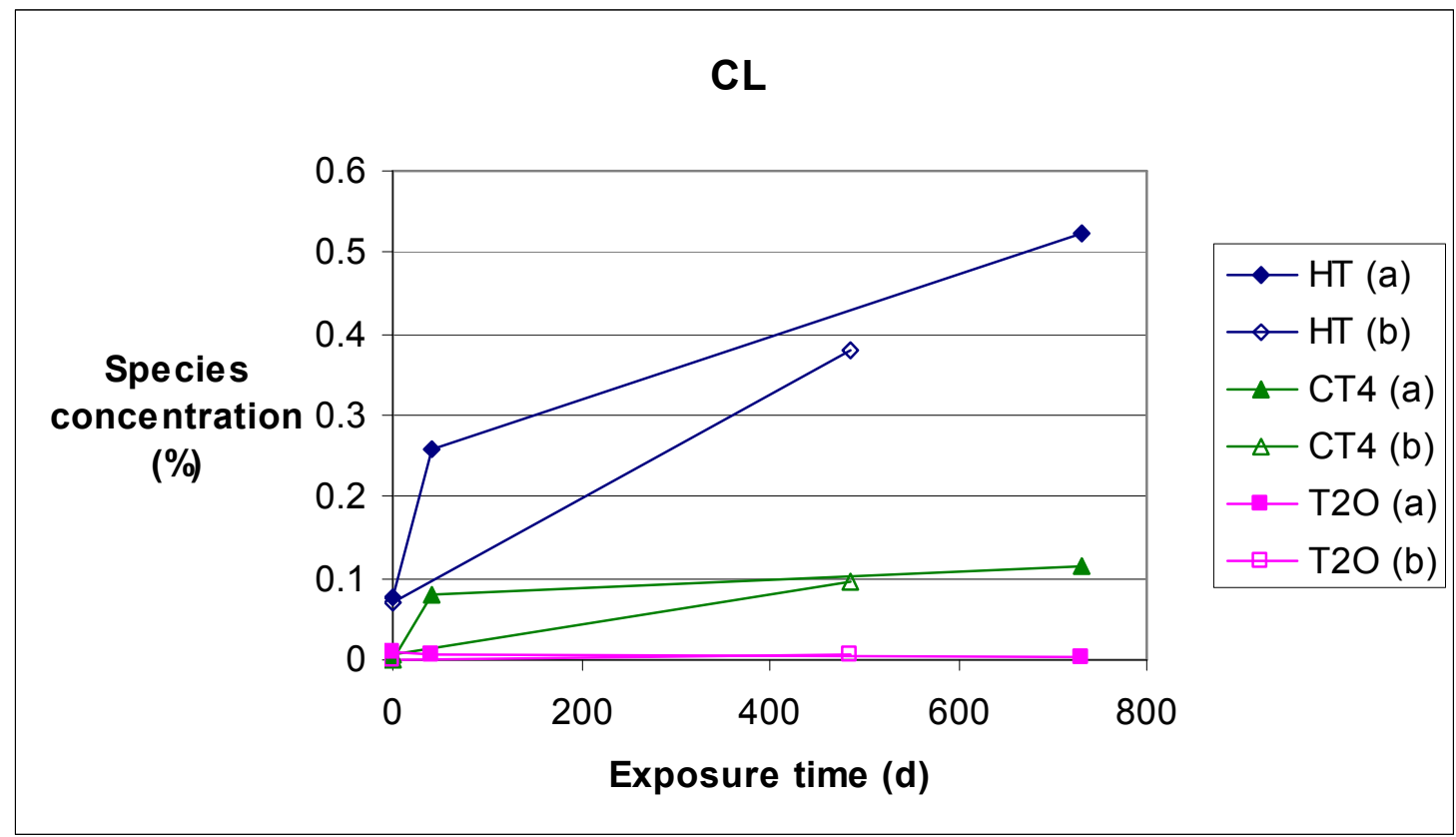

Figure 3-3. Species concentration (mole percent) versus exposure time for two CL containers (a and b); species indicated in legend.

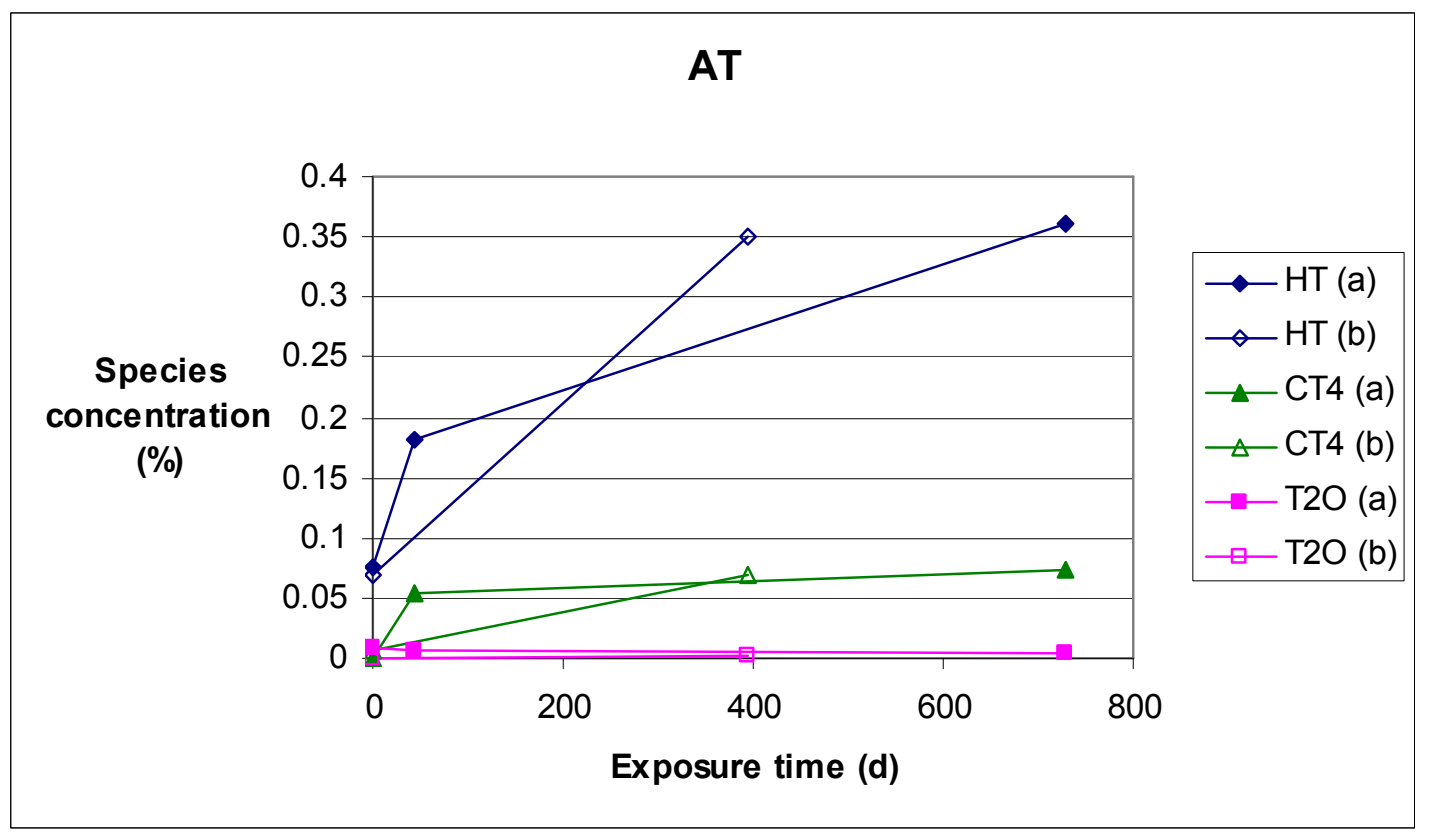

Figure 3-4. Species concentration (mole percent) versus exposure time for two AT containers (a and b); species indicated in legend. 


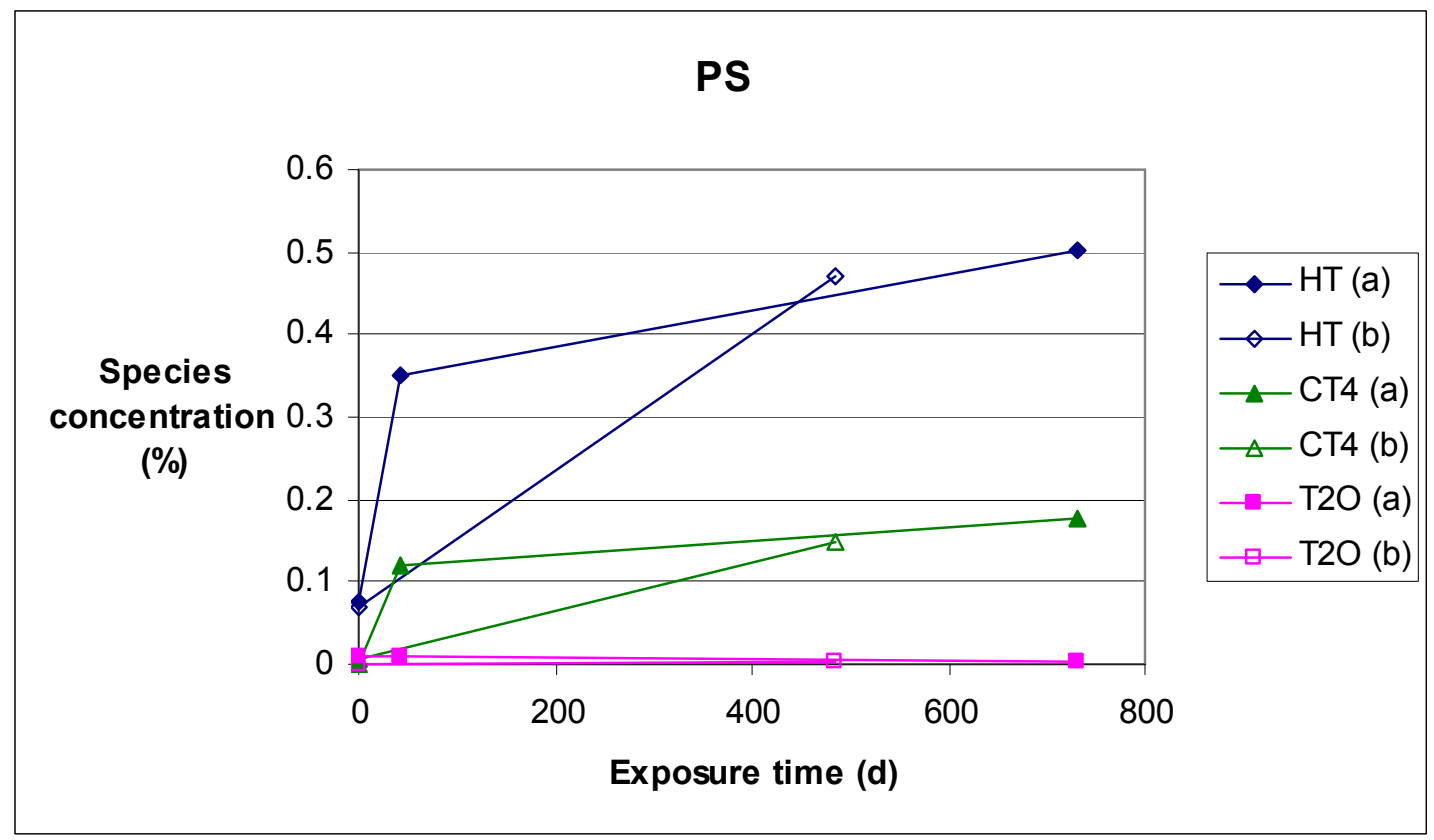

Figure 3-5. Species concentration (mole percent) versus exposure time for two PS containers ( $a$ and $b)$; species indicated in legend.

The "total impurities" can be found by summing the $\mathrm{HT}, \mathrm{CT}_{4}$, and $\mathrm{T}_{2} \mathrm{O}$ concentrations for each container. Plotting the total impurities for each container with exposure time in a single graph allows the performance of the different surface treatments to be directly compared (Fig 3-6). The currently used passivation method TK performed the best (had the least total impurity concentration); the next best was AT, then in order of increasing impurities CL, PS, and RK. 


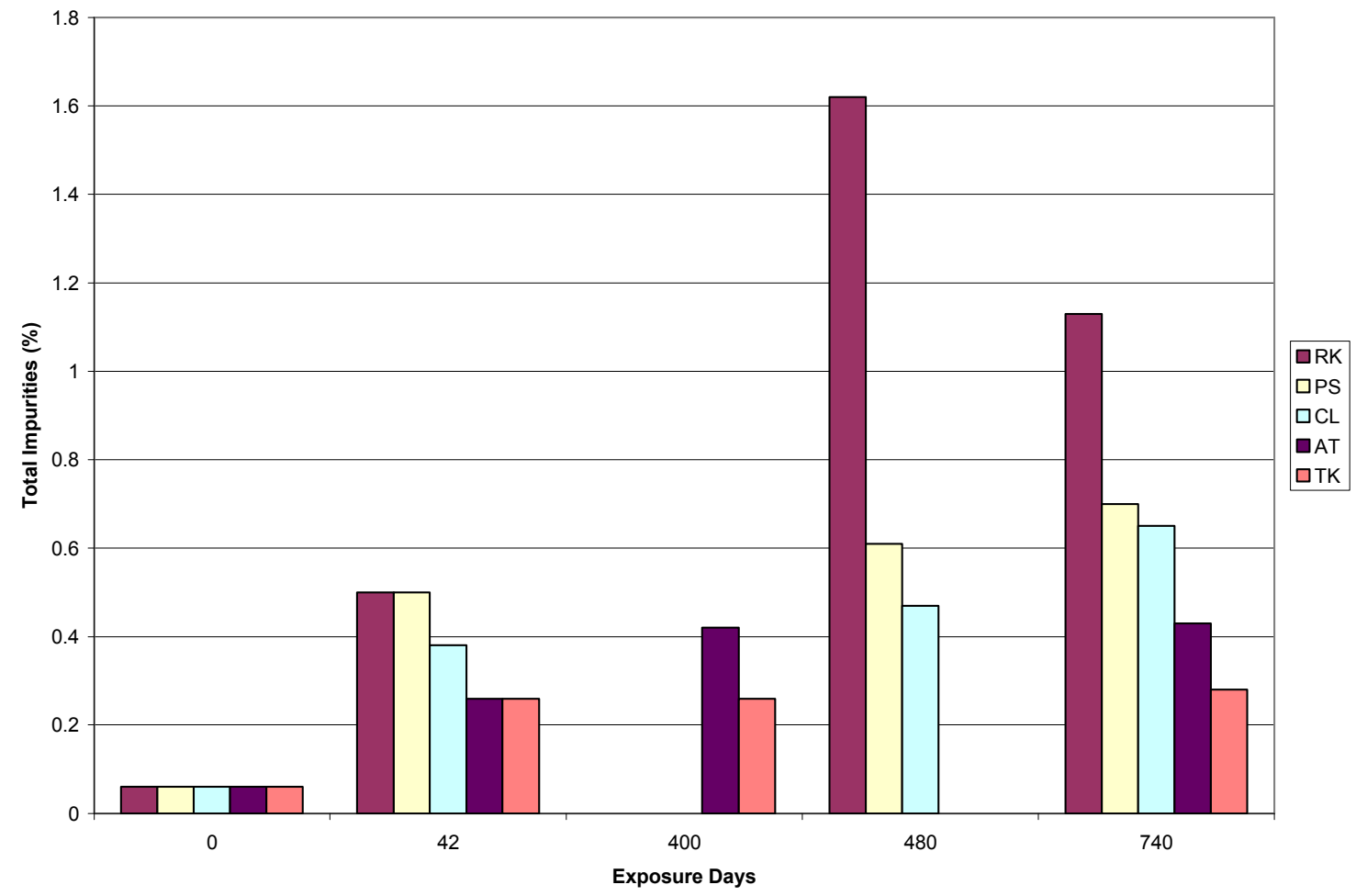

Figure 3-6. Total impurity concentration (mole percent) versus exposure time for all containers tested. Impurity levels increased with treatment order TK, AT, CL, PS, RK. 


\subsection{Summary and Conclusions}

Stainless steel containers having five different surface treatments applied by five different vendors were filled with pure tritium and the composition was determined by mass spectroscopy of samples taken over time from each. Observations and conclusions are:

1. In decreasing concentration, $\mathrm{HT}, \mathrm{CT}_{4}$, and a small amount of $\mathrm{T}_{2} \mathrm{O}$ were observed to appear with time for all the surface treatments studied. This observation agrees well with a previous study.

2. One of the currently used vendor treatments resulted in the smallest impurity levels in the tritium gas.

3. The silicon chemical-vapor-deposition treatment resulted in the highest impurity levels found in this study.

4. A cleaning procedure, in which pure tritium is contained in a new container for a month, should be considered.

\subsection{References}

1. "Surface Engineering of Stainless Steels", J.R. Davis, pp741- 761, in ASM Handbook® Volume 5- Surface Engineering, ASM International, Materials Park, Ohio USA (1994).

2. "Standard Specification for Cleaning, Descaling, and Passivation of Stainless Steel Parts, Equipment, and Systems", ASTM A380, ASTM International, West Conshohocken, PA USA.

3. "Standard Specification for Chemical Passivation Treatments for Stainless Steel Parts", ASTM A967, ASTM International, West Conshohocken, PA USA.

4. "Standard Specification for Passivation of Stainless Steel Using Electropolishing", ASTM B912, ASTM International, West Conshohocken, PA USA.

5. H.W. Kugel, H.F. Dylla, H.P. Eubank, T.A. Kozub, R. Moore, G. Schilling, L.D. Stewart, A. Von Halle, and M.D. Williams, J. Vac. Sci. Technol., 20(4), pp 1197-1200 (April 1982).

6. H.F. Dylla, D.M. Manos, PhH. LaMarche, J. Vac. Sci. Technol., 11(5), pp 2623-2636 (Sep./Oct. 1993).

7. Y. Tito Sasaki, J. Vac. Sci. Technol. A, 9(3), pp 2025-2035 (May/June 1991).

8. Y. Tito Sasaki, J. Vac. Sci. Technol. A, 25(4), pp 1309-1311 (Jul./Aug. 2007).

9. G. Hulquist, C. Leygraf, J. Vac. Sci. Technol. 17(1), pp. 85-88 (Jan./Feb. 1980).

10. J.T. Gill, J. Vac. Sci. Technol., 17(2), pp 645-653 (Mar./Apr. 1980).

11. J.T. Gill, W.E. Moddeman, R.E. Ellefson, J. Vac. Sci. Technol. A, 1(2), pp 869-873 (Apr.June 1983).

12. J.L. Maienschein, R. G. Musket, F.E. McMurphy, D.W. Brown, Appl. Phys. Lett., 50(14), pp 940-942 (1987).

13. E.A. Clark. "Evaluation of Alternate Stainless Steel Surface Passivation Methods", report WSRC-TR-2005-00246, Savannah River Site, Aiken, SC 29808 (31 May 2005). 